correct, there will be a very decided improvement made in the treatment of catarrh. Dr. G. Juhnson's treatment by full doses of opium invariably gives rise to unpleasant sequential symptoms, while Jukes Styrap's frequent minute doses with antimony are very depressing, to which I can bear personal testimony.

Loughrea.

\section{A WAISTCOAT-POCKET AURAL REFLECTOR AND SET OF SPECULA.}

BY E. CRESSWELL BABER, M.B. LOND,, SURGEON TO THE BRIGHTON AND SUSSEX TIIROAT AND EAR DISPENSARY.

IN comparison with some more favourably situated organs, such as the eye and the skin, the ear is placed at a dis. advantage, inasmuch as it usually requires for the diagnosis even of its more common diseases the use of certain instruments. It is therefore of importance that these instruments should be made as simple and portable as possible. A great step in advance in this direction was undonbtedly made when von Tröltsch introduced into general use the aural speculum and concave reflector, by means of which an ear can be inspected either with day light or artificial light. Under my direction Messrs. Millikin and Down of St. Thomas's-street, Borough, have modified these so as to render them still more portable. The reflector (Fig. 1, reduced in size) consists of two circular mirrors, each

FIG. 1.

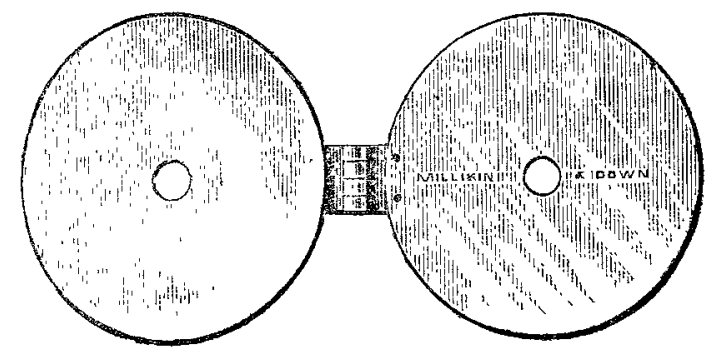

25 inch (about $6 \frac{1}{2}$ centimetres) in diameter, and firmly jointed together at the edge, so that when folded their reflecting surfaces come into contact. One mirror is made of glass and is concave, having a focal length of $5 \frac{1}{2}$ inches; the other is nickel-plated and plane. Both have a central circular aperture. With the concave mirror the ear may be examined either with ordinary daylight or with artificial light, whilst with the plane mirror sunlight may be reflected into the ear. The focal length of the concave mirror is purposely made rather long ia order that it may also serve for an examination of the nasal cavities from the front, and for throwing light into the fauces in inspecting that region. With this reflector and a bent hairpin to draw out the ala of the nose a very fair inspection of the nasal cavities can be made. The nest of specula (Fig. 2, natural size) con-

FIG. 2.

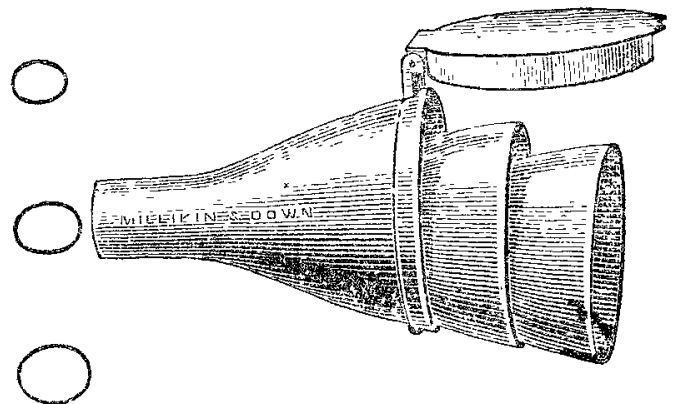

sists of three, made of silver, fitting accurately one into the other. They are shorter than those in common use (neasuinin 3 centimetres- $1 \frac{1}{2}$ in.-in length), and are inare as light as possible. The smaller ends of the specula meisure respectively about 6 by 7,5 by 6 , and 4 by 5 millimetres in diameter. The largest speculam, measuring at its broad end 17 by 18 millimetres in diameter, is titted with a cap, which is preferably jointed on to the flatter side of the speculnm, and nut to the end of the oval, as shown in the figure. The shortness of the specnla does not interfere, I have found, in any way with their practical utility, although, of course, they afford less leverage for moving them in the ear than the ordinary specula. With these two small instruments in his pocket, the practitioner can, at a moment's notice, inspect an auditory canal and gain important information as to the state of a patient's ear. Others, no doubt, like myself, have frequently been requested to look at So-and-so's ear, as he or she was suffering from earache or deafness. Instead of deferring one's examination to a future period, with these instruments at hand the auditory canal can be immediately examined, and the case prescribed for on rational principles. If, for instance, the meatus be occluded with cerumen, instillations of a solution of bicarbonate of soda can be ordered, which will facilitate its removal with the syringe at the next visit; if the meatus be filled with pus, directions can be given to syringe the ear with warm water; if the meatus be clear, and the membrane shows signs of acute inflammation, or of inflammation in the drum cavity, the immediate application of a leech in front of the tragus will probably be of great benefit, and any other instruments likely to be required, such as the Politzer bag or paracentesis needle, can be brought at a subsequent visit. Without multiplying instances, it is self-evident that, especially in acute cases, such as are met with in general practice, the earlier a case is examined the more successful and satisfactory the treatment is likely to be.

\section{AN EVACUATOR FOR THE BLADDER.}

BY JOHN H. MORGAN, F.R.C.S. ENG., CHARING.CROSS HOSPITAL.

IN a lecture published in the number of THE LANCET for January 7th, 1882, Sir Henry Thompson describes an aspirator which had been made according to his own design, and another modification of the same principles carried out by Messrs. Weiss and Sons, and he lays down some points as essential in the construction of an efficient instrument. The first of these principles is that "it should be light and smail, so as to be easily grasped and governed by one hand"; the second requires that there should be a tap at the top for the exit of air and the introduction of water. To fulfil these conditions is not an easy matter, since any apparatus of india-rubber which is to support above a heavy tap and be attached below to a cylindrical glass receiver in which frag. ments are caught, and to which a catheter is attached, must be of such density and size as to be with difficulty grasped, much less compressed by a single hand, at all events many times in succession. In other words, if the continuity of the bulb is broken at two points, its resiliency must be supplied by greater thickness. This objection is practically found in the case of both these instruments. At the late meeting of the Medical Congress in London, Professor Bigelow explained that "the new and essential part of the evacuating apparatus is the large catheter, whether straight or curved," and went on to describe the various apparatus which he has contrived to extract fragments from the bladder, and at the same time to prevent the possibility of their return. These instruments were figured and deseribed in the Transactions, but that Professor Bigelow is hardly yet satisfied is shown by the fact that at a recent meeting of the New York Academy of Medicine he exhibited the evacuator which he has "finally settled down upon as being the best," adding that the ball-valve and strainer which formed part of his former instrument were a "little complicated" and "apt to clog."

Adhering to the principles laid down by these two eminent lithotritists, I have been at some pains to contrive an apparatus which should at once be effective in action, but of simpler construction than those hitherto invented. The result of my eflorts is an instrument which is figured below. It consists of an india-rabber bulb (A) of moderate resiliency, and capable of containing about twelve ounces of water. This is of the shape of an inverted pear, and its narrow portion is fixed to a metal ring, which can be attached to or removed from the central portion of the apparatus by means of a screw. This is only required for convenience of carriage or for the purpose of cleaning the apparatus. In order to allow a better view of the glass-receiver, the bulb is attached at an angle slaniing backwards to the rest of the apparatus, which hangs perpendicularly. The central portion is of metal, 